\title{
PROGRESS IN COASTAL OCEAN MODELING DURING COOP
}

BY ROGER M. SAMELSON, JOHN S. ALLEN, AND PARKER MACCREADY

ABSTRACT. Numerical modeling of coastal ocean circulation underwent a sea change during the CoOP years. In the late 1980s and early 1990s, when CoOP was conceived and implemented, most of the focus in modeling subinertial coastal circulation was on the linear, first-order wave equations of coastal trapped wave theory. The early years of CoOP that followed coincided with the initial development of three-dimensional, primitive-equation numerical models of the coastal ocean, which had first appeared during the preceding decade. By the late stages of CoOP, advanced data assimilation methods were being used with high-resolution primitive-equation models that included detailed nonlinear parameterizations of the effects of stratified boundary layer turbulence to explore the complex dynamics of windand buoyancy-driven coastal ocean flow over realistic shelf and slope topography. The improved realism and accuracy of these models facilitated progress in ecosystem modeling as well. 


\section{INTRODUCTION}

The coastal ocean is a dynamic physical environment, rich with marine life and of great societal and economic importance. Much of its special oceanographic character stems from the influence of the coastal boundary on the circulations induced in the ocean by winds, tides, and other natural forces. These circulations exert powerful control over the coastal environment, and to understand the general oceanography of the coastal zone, it is therefore necessary to understand these physical processes. Accordingly, the central, defining goal of the Coastal Ocean Processes (CoOP) program, as expressed in the original science prospectus (Brink et al., 1992), was to obtain a new level of quantitative understanding of the processes that dominate the transports, transformations, and fates of biologically, chemically, and geologically important matter on the continental margins.

The emphasis on interdisciplinary collaboration implied by this goal was characteristic of the CoOP program. The emphasis on the importance of material transport, which arose from the recognition that the three-dimensional fluid circulation over the continental shelf defines and controls the physical environment for all coastal marine processes, was presaged by an earlier national working group (Brink et al., 1988) that formulated a more specific goal for the coastal physical oceanography community:

to develop a quantitative understanding of the processes which, on time scales of hours to years, dominate the transport of matter, momentum, and energy across the continental margin.
This working group further asserted that [n]ow is an ideal time for the achievement of major advancements in modeling capabilities for coastal physical oceanography...[T]he recent availability of supercomputer resources, coupled with continued development of numerical and analytical techniques, has provided new tools...[I]t is clear that...modeling work should form an essential part of a national program for coastal physical oceanography.

Over the next two decades, many of these anticipated developments and opportunities came to fruition, bearing out of the insights of the founders of CoOP.

\section{COASTAL OCEAN}

\section{CIRCULATION MODELING}

The basic objective of physical modeling of coastal circulation is to provide an accurate description of the motion and thermodynamic composition of the ocean's waters, given knowledge only of processes operating at the ocean's boundaries, such as the force of the wind on the sea surface. The techniques by which this modeling of coastal ocean circulation was carried out underwent dramatic change during the $\mathrm{CoOP}$ years.

In the late 1980s and early 1990s, when CoOP was conceived by the coastal ocean science community and then implemented as a National Science Foundation (NSF) research program, with supplemental support from the Office of Naval Research (ONR) and the National Oceanic and Atmospheric Administration (NOAA), most of the focus in coastal ocean modeling was on the linear, first-order wave equations of coastal trapped wave theory (Brink, 1991). These equations, which provided the basis for most quantitative comparisons of model results with coastal physical observations during this period, gave an approximate description of some of the dominant features of the subinertial (low-frequency, relative to the local vertical component of Earth's angular velocity) coastal circulation, such as the strength of alongshore flow over the shelf and the fluctuations in coastal sea level; however, they were unable to provide any details of the three-dimensional circulation over the complex seafloor topography that characterizes all but the simplest coastal regions. A parallel community effort during this period was the use of numerical models to study tides and storm surges; these efforts to model higher-frequency phenomena were important in their own right, but were generally restricted to depth-independent, unstratified representations of the flow, and they had limited scientific overlap with the interdisciplinary goals that motivated $\mathrm{CoOP}$.

The early years of CoOP that followed coincided with initial development of primitive-equation numerical models of the coastal ocean, which had first appeared during the preceding decade (Heaps, 1987). These models began to resolve the intricate interlinking of circulation and topography, using sophisticated parameterization schemes to represent the effects of small-scale turbulent boundary layer processes adjacent to the sea surface and seafloor.

By the late stages of CoOP, advanced data assimilation methods, similar to those developed for global numerical weather prediction systems, were being used with high-resolution primitiveequation models to explore the complex, three-dimensional dynamics of coastal 
ocean flow over realistic shelf, slope, and estuarine topography, and the dynamic coupling of coastal ecosystems to physical circulation.

\section{COASTAL MODELING}

\section{AND COOP}

Wind-driven Continental Shelf Flows Over Complex Topography

The wave equations of coastal trapped wave theory are based on linear dynamics, forced by alongshore wind stress fields estimated from coastal buoys or land stations, and damped with a simple frictional drag (Gill and Clarke, 1974; Gill and Shuman, 1974; Allen, 1980). They were remarkably successful in hindcasting observed coastal sea level and alongshore velocities, and they demonstrated that the response of the sea level and alongshore velocities at a given point along an eastern boundary coast depended strongly on the coastal winds over a region extending several hundred kilometers equatorward of the given point (Battisti and Hickey, 1984; Halliwell and Allen, 1984; Church et al., 1986; Mitchum and Clarke, 1986). These comparisons of linear theories with observations, carried out in many different regions, including Peru, East Australia, and West Florida as well as the US West Coast, had established the

Roger M. Samelson(rsamelson@coas. oregonstate.edu) is Professor, College of Oceanic and Atmospheric Sciences, Oregon State University Corvallis, OR, USA. John S. Allen is Professor Emeritus, College of Oceanic and Atmospheric Sciences, Oregon State University Corvallis, OR, USA. Parker MacCready is Associate Professor, School of Oceanography, University of Washington, Seattle, WA, USA. essential role of coastal trapped waves in coastal ocean circulation shortly before CoOP was conceived (Brink, 1991).

The object of the first CoOP project, the Inner Shelf Dynamics experiment, which took place at Duck, North Carolina, in 1992, was to study transport on inner shelves. The inner shelf is the shelf region adjacent to the surf zone, where the water is shallow enough that the direct influence of the top and bottom boundaries is felt throughout the water column; typically, this corresponds to water depths of $30 \mathrm{~m}$ or less. This region had not been widely studied because the shallow water and the strong wave activity on the inner shelf pose technical challenges for maintaining moorings and operating ships. Modeling associated with the Duck inner-shelf program focused initially on understanding basic physical processes relating to the adjustment of alongshore flow in a stratified fluid over a sloping bottom in the presence of a turbulent bottom boundary layer (Chapman and Lentz, 1997), and on the smaller-scale problem of breaking surface gravity waves in the surf zone (Chen et al., 1997). Idealized two-dimensional modeling of the winddriven upwelling and downwelling response was carried out several years later (Austin and Lentz, 2002). Some modeling of episodic events during the CoOP Great Lakes projects has also been carried out (Eadie et al., this issue; Lohrenz et al., this issue), but it is not covered here.

It was in the Coastal Advances in Shelf Transport (COAST) and Wind Events and Shelf Transport (WEST) projects that numerical coastal ocean models began to be used systematically in CoOP to address the challenging problem of understanding the three-dimensional structure of wind-driven shelf flows over complex topography, and quantifying the associated cross-shelf transports of matter, momentum, and energy. Such an approach had originally been proposed and explored many years earlier (O’Brien and Hurlburt, 1972; Peffley and O'Brien, 1976), prior to the revolutionary advances in both computational and observational technology that ultimately made the realistic simulations and comprehensive model-data comparisons during CoOP possible. Equally notable are pioneering efforts made during CoOP to develop and analyze coupled biophysical models of coastal ecosystems. It should be emphasized that important progress during this period was also made through other programs; attention here is necessarily restricted to a brief review of some of the CoOP contributions.

Central to the scientific hypotheses of the COAST project were questions related to the temporal and spatial variability induced in the across-shelf transport off Oregon by energetic mesoscale (5-50-km horizontal scale) features in the shelf flow and its resultant implications for the biology and chemistry. These features included effects of alongshore variations in topography that, as evident from satellite sea surface temperature images during summer (Figure 1), clearly exert a major influence on the mesoscale shelf flow response to upwelling-favorable winds. Primary time scales of interest for fluctuations in the mesoscale flow include those imposed by atmospheric forcing (i.e., several days and longer). To address the above hypotheses, the COAST project conducted field experiments off the Oregon coast in May-August 2001, during 
summer upwelling conditions, and in January-March 2003, during winter downwelling conditions. Measurements were concentrated between $43.8^{\circ} \mathrm{N}$ and $45.2^{\circ} \mathrm{N}$ in a region (Figure 1) that includes relatively regular shelf topography around $45^{\circ} \mathrm{N}$ and more complex topography associated with Heceta Bank between $43.8^{\circ} \mathrm{N}$ and $44.5^{\circ} \mathrm{N}$. Supporting modeling studies included applications of physical circulation models, coupled ecosystem models, and mesoscale atmospheric models. In particular, the physical circulation and ecosystem modeling efforts were focused on representing and studying the behavior of the wind-driven, subinertial frequency, mesoscale circulation over the continental shelf during the 2001 summer upwelling experiment.

The COAST physical circulation modeling used finite-difference approximations to the hydrostatic primitive equations (Blumberg and Mellor, 1987; Shchepetkin and McWilliams, 2005) with a sophisticated turbulence submodel (Mellor and Yamada, 1982). High-resolution (1.5-2-km) horizontal grids in limited-area domains, extending alongshore $350-600 \mathrm{~km}$ and offshore 220-250 km and centered in latitude around $44.7^{\circ} \mathrm{N}$, were utilized with realistic shelf and slope bottom topography. For most of the initial studies, periodic boundary conditions were applied at the open northern and southern boundaries; previous comparisons with data (Oke et al., 2002) had indicated that these provide a useful approximation for the strongly wind-driven flows over topography. The circulation models were run for time periods corresponding to the field experiments, with time-dependent surface heat fluxes and spatially uniform wind stress obtained from bulk aerodynamic formulae and meteorological observations from coastal buoys, filtered to remove diurnal and higher-frequency fluctuations. Tidal and river forcing were not included. The models were integrated from rest, with initial stratification typical of observed May conditions just offshore of the shelf. The model studies included a direct simulation (Gan and Allen, 2005) and also a set of experiments involving assimilation of COAST moored current meter measurements (Kurapov et al., 2005a, b, c; also supported by ONR). The ecosystem response on the shelf was studied by Spitz et al. (2005) using a fivecomponent, nitrogen-based ecosystem model coupled to the physical circulation model of Gan and Allen (2005) and run in a simulation mode for the time period of the COAST field experiment. The five components of the ecosystem model were nitrate, ammonium, phytoplankton, zooplankton, and detritus; initial conditions were horizontally uniform with vertical distributions of nitrate and phytoplankton taken from offshore observations at the beginning of the field experiment.

COAST project measurements of depth-dependent currents and temperatures from moorings and towed hydrographic instruments were used for model-data comparisons in the physical simulation model experiment by Gan and Allen (2005). More extensive data sets were used for comparisons in the data-assimilation-based study by Kurapov et al. (2005b). Varying amounts of agreement have been found and documented. Importantly, the response of the shelf circulation to time-dependent wind stress forcing and the interactions

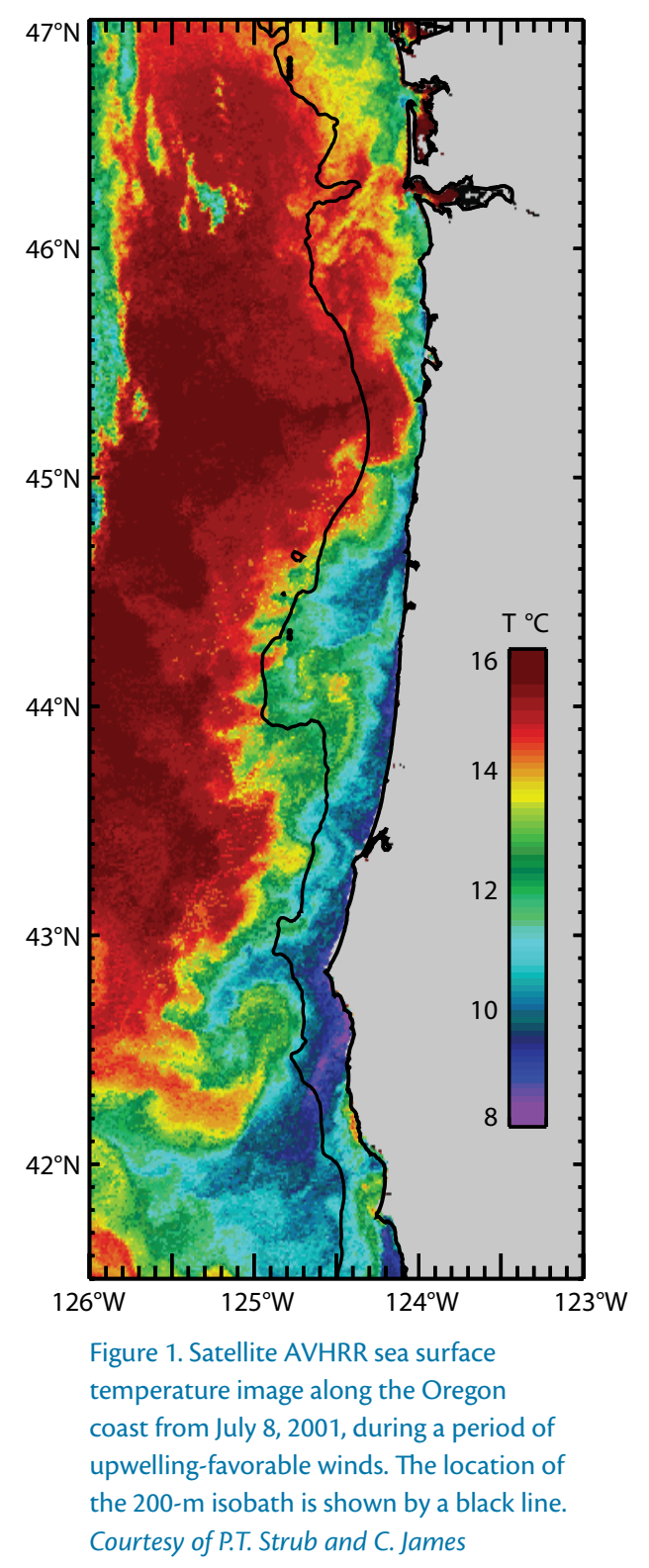

of the shelf flow with mesoscale topographic features appear to be reasonably well represented.

Results from Spitz et al. (2005) illustrate some basic features of the modeled Oregon shelf flow and ecosystem response. Comparisons of sea-surface chlorophyll $a$ fields from two eight-day composite SeaWiFS satellite images, during conditions of low cloud coverage, with corresponding fields from the ecosystem modeling simulation 
(Figure 2), generally show qualitatively similar spatial and temporal variability. Surface velocity vector fields from the coupled physical circulation model are superposed. The effect of the alongshore topographic variations associated with Heceta Bank, between $43.8^{\circ} \mathrm{N}$ and $44.5^{\circ} \mathrm{N}$, on the mesoscale distribution of the observed and modeled chlorophyll $a$ fields and on the modeled velocity fields is clear. In particular, in the region of concentration of the COAST field experiment, between $44^{\circ} \mathrm{N}$ and $45^{\circ} \mathrm{N}$, the southward alongshore current or coastal jet is notably stronger during the July 20-27 period of upwelling-favorable winds than it is during the August 5-12 period following downwelling-favorable winds. The jet tends to follow the isobaths offshore on Heceta Bank during both time periods, leaving a region of much weaker flow inshore. Relatively high values of chlorophyll $a$ are also seen to extend offshore over Heceta Bank and to have generally larger magnitudes during the July 20-27 period of upwelling. It is evident that ecosystem behavior is strongly coupled to that of physical circulation, which in turn has a major dependence on wind forcing and shelf topography. The relative roles of physical and biological processes in determining the ecosystem response were examined further by Spitz et al. (2005) (see Box 1).

The COAST array of moored acoustic Doppler profilers, consisting of two across-shelf lines of three moorings each at $45^{\circ} \mathrm{N}$ and $44.2^{\circ} \mathrm{N}$ (Figure 3), was designed to provide horizontal current measurements from regions of both relatively regular shelf topography at $45^{\circ} \mathrm{N}$ and more complex topography over Heceta Bank at $44.2^{\circ} \mathrm{N}$. The resulting measurements were utilized in Kurapov et al. (2005a) for data assimilation studies with a sequential optimal interpolation algorithm. A relevant characteristic of the model simulations without data assimilation is that they have much better success in representing the observed currents at $45^{\circ} \mathrm{N}$, where the southward coastal jet is found near the coast, than they do farther south over Heceta Bank at $44.2^{\circ} \mathrm{N}$, where the jet has typically
July 20 - July 27, 2001

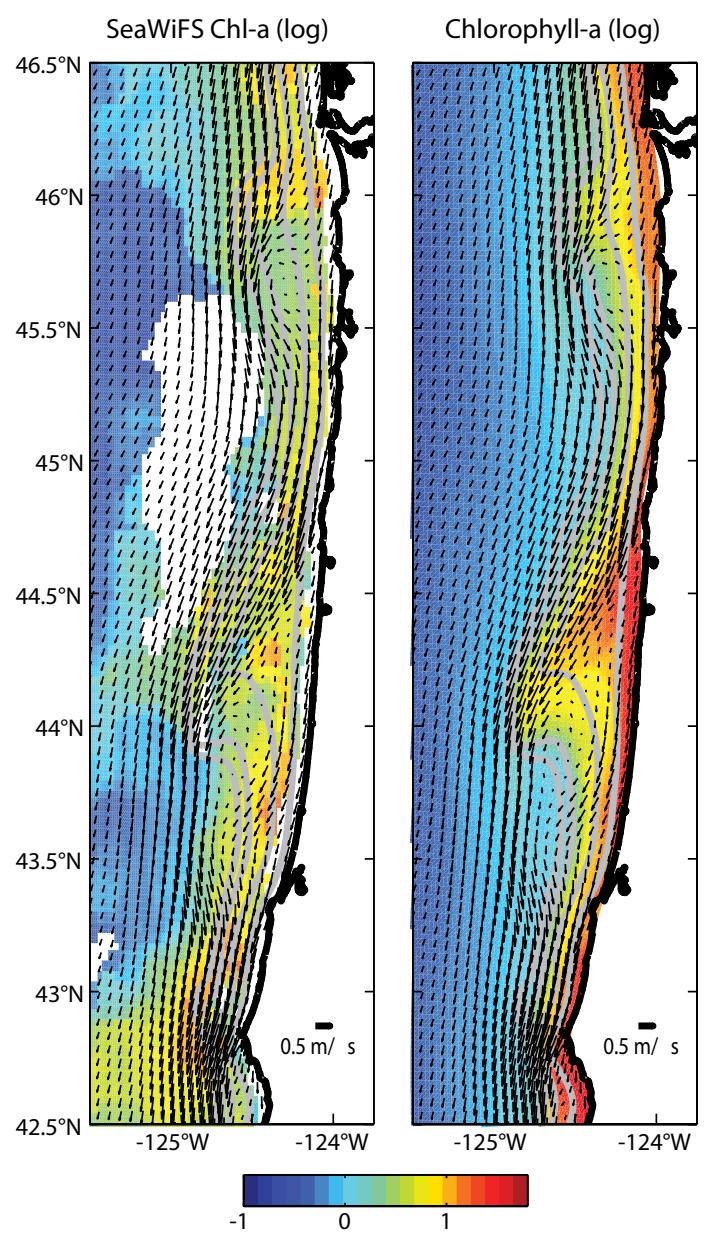

August 5 - August 12, 2001

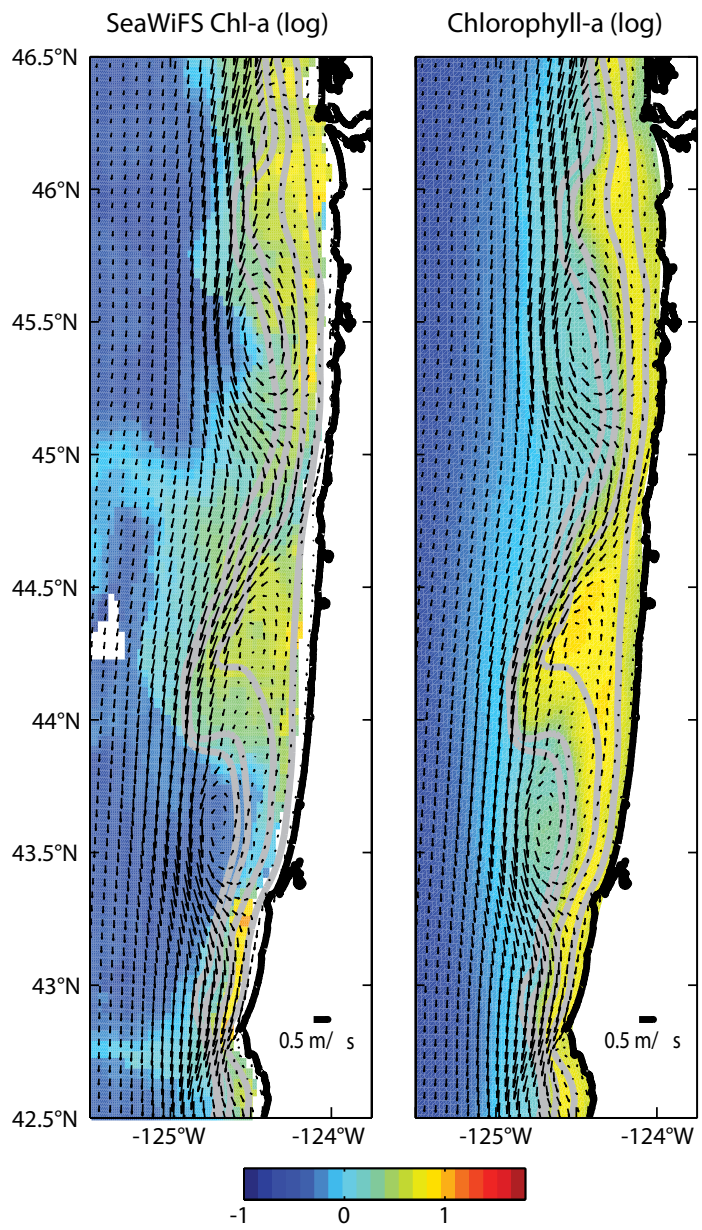

Figure 2. SeaWiFS and modeled surface chlorophyll $a$ $\left(\mathrm{mg} \mathrm{Chl} \mathrm{m} \mathrm{m}^{-3}\right.$ ) along the Oregon coast during a period of sustained upwelling wind, July 20-27, 2001 (left two panels), and during a period following downwelling wind, August 5-12, 2001 (right two panels). The arrows represent the mean surface velocity vectors over the two chosen periods. The 50-, 100-, 150-, and 200-m isobaths are shown by grey lines. Note that there are almost no SeaWiFS observations shoreward of the 50-m isobath. Adapted from Spitz et al. (2005) 


\section{BOX 1. PHYSICAL-BIOLOGICAL COUPLING}

CoOP-supported research revealed connections between physical circulation and the distribution of biological properties on the continental shelf. To investigate the relative importance of physical and biological controls on ecosystem response, two 10-day periods with strongly contrasting wind conditions were selected for detailed analysis during the COAST project. These time periods, designated as R1 (June 3-12) and R2 (July 1-10; see Figure 1), were dominated, respectively, by downwelling- and upwelling-favorable winds. Gan and Allen (2005) examined the differing dynamical characteristics of the physical circulation processes during these periods. Spitz et al. (2005) determined the time-averaged contributions of physical (advection and diffusion) and of biological (ecosystem source and sink terms) processes to the total timerate of change in the phytoplankton concentration at the surface (Figure B1). During R1, the phytoplankton concentration decreases over the shelf and in a region extending offshore over Heceta Bank. This decrease is a result of zooplankton grazing that is larger than phytoplankton growth, which is relatively small due to the decreased nutrients at the surface, and larger also than the positive accumulation effects of the physics onshore of the coastal jet. During upwelling in R2, on the other hand, high phytoplankton growth results from the increase in supply of nutrients and leads to an increase in the phytoplankton concentration, especially inshore of the coastal jet on the north part of Heceta Bank. Physical forcing in that region provides a negative contribution, resulting from the advection offshore of upwelled water with low concentrations of phytoplankton. In addition, an indirect positive coupling with biological forcing exists, because the increase in nutrient supply is related to physical circulation. It is notable that the direct contributions to the net change in phytoplankton concentrations over Heceta Bank from physical and biological processes have comparable amplitudes, generally oppose each other but with the biological processes dominating, and have effects of opposite sign during R1 and R2.
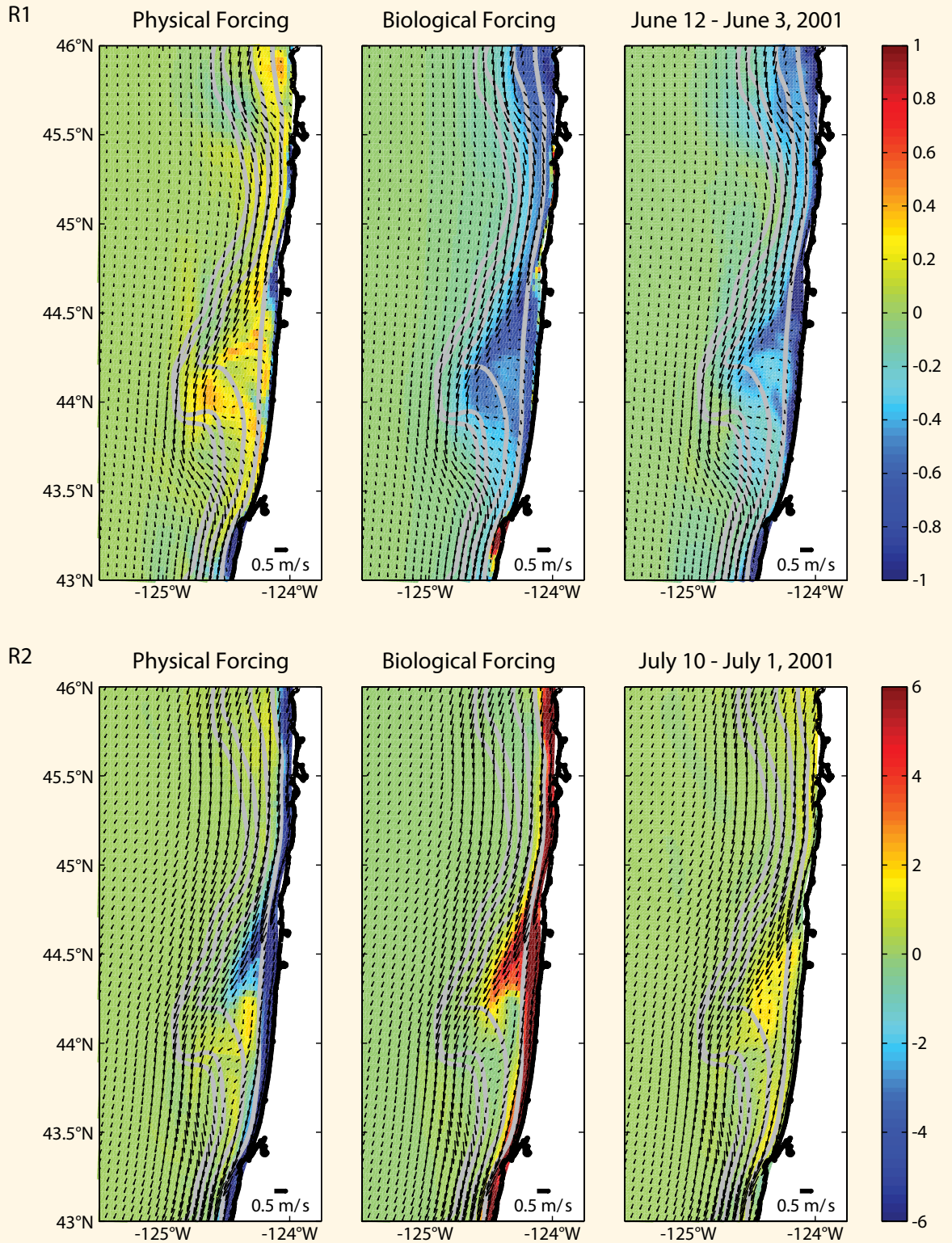

Figure B1. Time-averaged surface physical and biological balances $\left(\mathrm{mmol} \mathrm{N} \mathrm{m} \mathrm{m}^{-3}\right)$ for the phytoplankton over a downwelling period (R1, June 3-12) and an upwelling period. (R2, July 1-10). The biological forcing is the sum of the ecosystem source and sink terms, and the physical forcing (left panels) and biological forcing (center panels) equals the integrated time difference term (final state minus initial state; right panels). All the terms, except the time-rate of change, are considered as on the right-hand side of the phytoplankton equation. As a result, the sum of the physical forcing on the left and the biological forcing in the center equals the integrated time difference term (final state minus initial state) on the right. The superposed vector fields represent the mean surface velocity over the time period considered. Adapted from Spitz et al. (2005) 

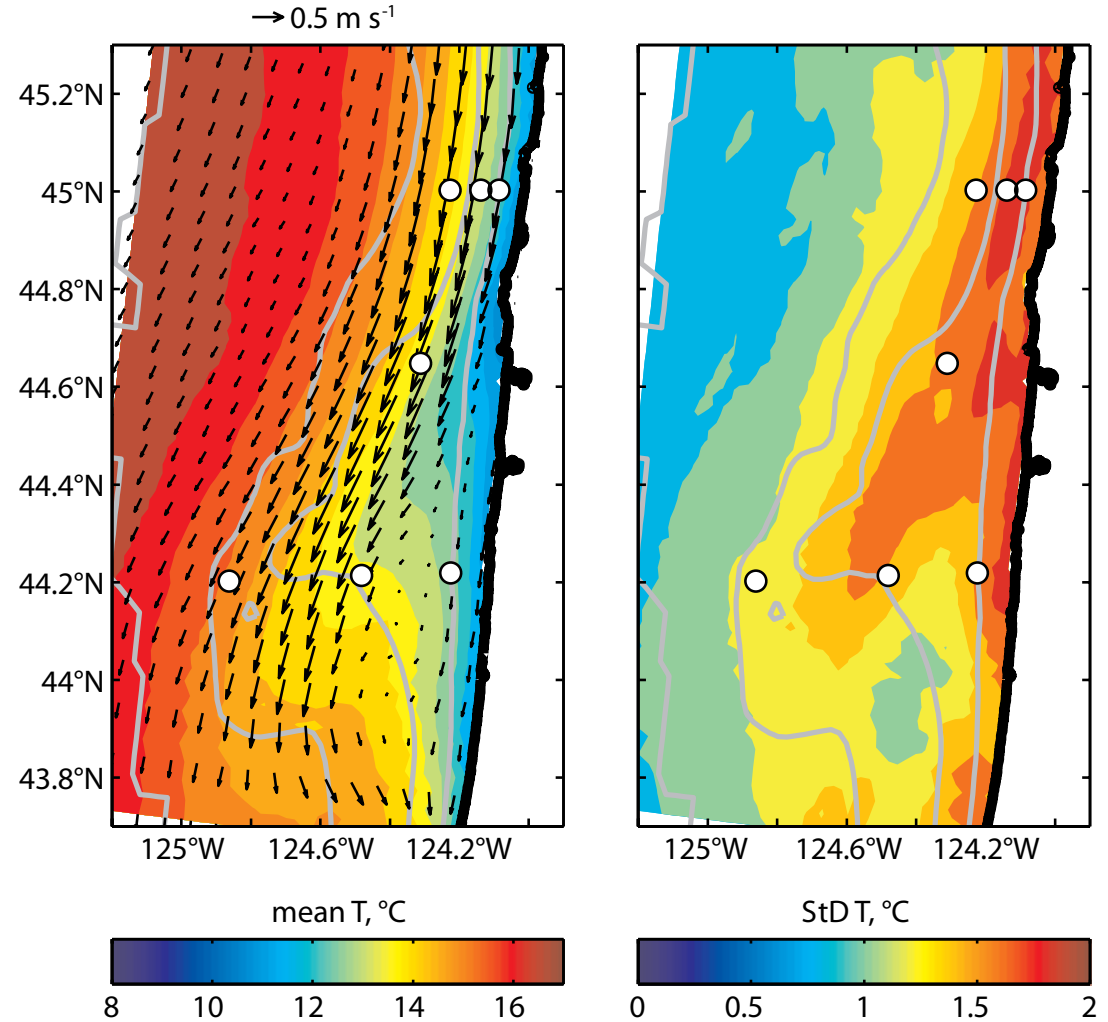

Figure 3. (Left) Time-averaged surface velocity (vectors) and temperature (color) fields for days 146-191 from the case with assimilation of velocity measurements from the moorings on both the north line $\left(45^{\circ} \mathrm{N}\right)$ and the south line $\left(44.2^{\circ} \mathrm{N}\right)$. (Right) Corresponding temperature standard deviation fields. The mooring locations are indicated by circles. The 50-, 100-, 200-, and $1000-\mathrm{m}$ isobaths are shown by grey lines, and the black line denotes the coastline. Velocity vectors are shown at every third grid cell. Adapted from Kurapov et al. (2005b)

separated from the coast with an offshore location that is an irregular function of time. Consequently, the desired corrections to the velocity field from data assimilation can be expected to be larger over Heceta Bank. An important finding there, relevant to design considerations for future coastal observing systems, was that assimilation of current measurements along the northern line at $45^{\circ} \mathrm{N}$ substantially improves the model/data agreement $90 \mathrm{~km}$ to the south at $44.2^{\circ} \mathrm{N}$ and that the improvement evidently occurs through the effects of southward advection. It was also found that assimilation of the current measurements from mid- and outer-shelf moorings on the southern line at $44.2^{\circ} \mathrm{N}$ improved the model agreement $90 \mathrm{~km}$ to the north, in this case evidently through the mechanism of northward coastal trapped wave propagation. An attempt was also made to use the data assimilation results to obtain information about possible modeling deficiencies. An analysis of the time- and depth-averaged terms in the alongshore momentum equation showed that the effect of the correction due to data assimilation generally corresponded to a retarding force, similar to an increased bottom friction, opposing the southward current. That type of correction could result from several possible causes. Inclusion of high-frequency tidal motion may result in an increase in bottom stress. Unresolved internal wave drag on small topographic features may be appreciable and require parameterization. Large-scale alongshore pressure gradients, disallowed by the periodic boundary condition, may be important. The representation and implementation of atmospheric forcing may need to be improved. The important point is that the assimilation analysis has provided quantitative dynamical information that is relevant for improving the modeling system (Box 2).

The WEST project's overall goal was to understand the role of wind-driven shelf transport in biological productivity over the northern California shelf in the region around Point Reyes $\left(38^{\circ} \mathrm{N}\right)$. That location was generally the same as that of CODE (Coastal Ocean Dynamics Experiment) in the summers of 1981 and 1982. Prior to the execution of either the WEST or COAST field experiments, the CoOP program supported modeling efforts (Gan and Allen, 2002a, b) on wind-driven shelf systems that took advantage of the extensive CODE analyses and data sets and performed process studies and simulations for summer 1982. A limited area domain with a high-resolution grid and realistic topography, similar to the setup for the COAST experiment described above, was used for the CODE region. One motivation for the process study was to better understand the characteristic shelf flow response observed during CODE that involved the time-dependent development of northward currents over the inner shelf next to the coast following the weakening, or relaxation, of southward upwelling-favorable winds. Advection of warm surface water northward around Point Reyes was one striking feature observed. These relaxation 


\section{BOX 2. DATA ASSIMILATION AND COASTAL OCEAN DYNAMICS}

CoOP-supported research demonstrated that data assimilation methods can be used in the coastal ocean to obtain new understanding by melding observations with dynamical models. Assimilation of velocity measurements from all six moorings at $45^{\circ} \mathrm{N}$ and $44.2^{\circ} \mathrm{N}$ during the COAST project (see Figure 3) were shown in Kurapov et al. (2005b) to have positive effects on other variables, including temperature, potential density, sea surface height, and near bottom turbulence parameters. One notable aspect of that study involved the comparison of small-scale turbulent dissipation rates from microstructure measurements, averaged in depth over the bottom $25 \mathrm{~m}$, with corresponding model values from the Mellor and Yamada (1982) turbulence parameterization. Reasonable agreement, markedly improved in the solutions with data assimilation presumably through correction of the modeled near-bottom velocities, was found. This improvement in the near-bottom currents, and thus in the representation of the bottom boundary layer, was exploited in Kurapov et al. (2005c), where another physical effect of the influence of topography on the shelf flow was found. Although the modeled bottom mixed layer thickness at $45^{\circ} \mathrm{N}$ decreased during upwelling winds and increased during downwelling winds, in accordance with prior theoretical expectations, the opposite behavior was found on the inshore side of the coastal jet over Heceta Bank. The behavior in that location was shown, using the curl of the model bottom stress field, to be related to Ekman pumping in the bottom boundary layer, induced by acrossshore gradients in the separated alongshore coastal jet (Figure B2). Increased values of modeled turbulent kinetic energy in the bottom boundary layer, related to associated convective instabilities induced by horizontal advection, were also found in the same location. This study provides a good example of model-assisted analysis of shelf flow behavior that could have a substantial impact on the time and space distribution of across-shelf transport and that would be practically impossible to extract from observations alone.
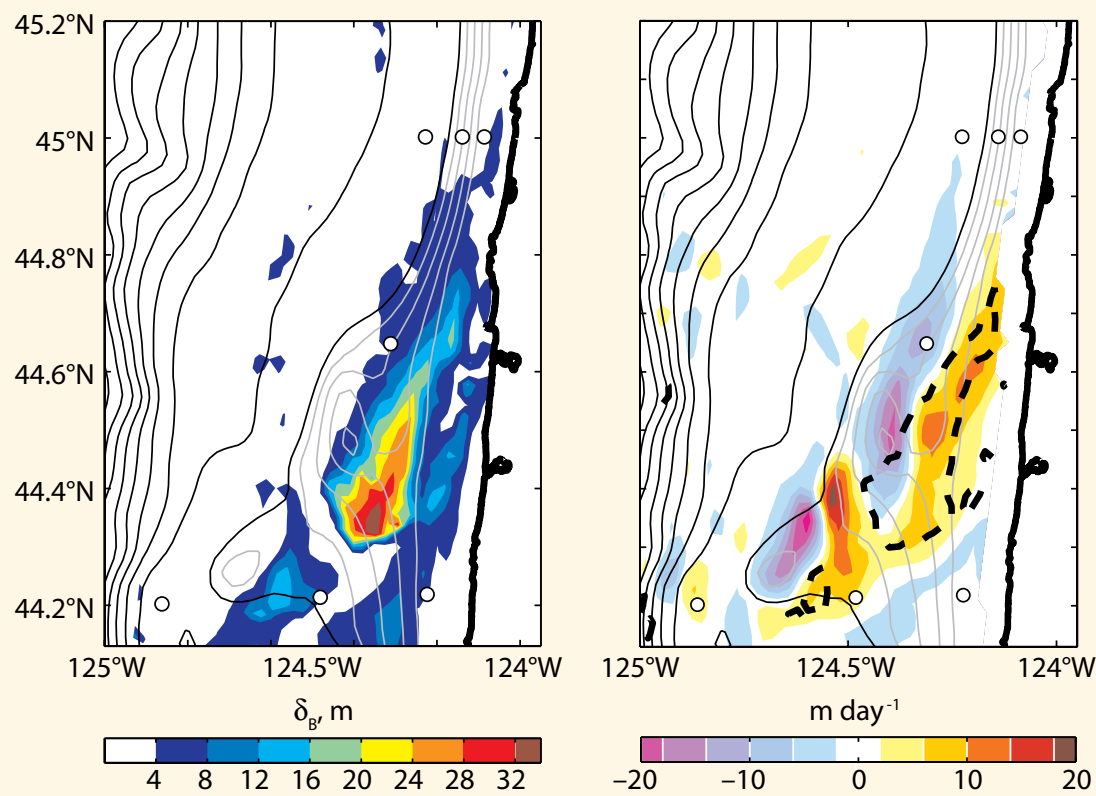

Figure B2. (Left) Daily averaged bottom mixed layer (BML) thickness (shown for depths less than $250 \mathrm{~m}$ ) for day 170 when the winds are strongly upwelling favorable. (Right) Corresponding daily averaged bottom Ekman vertical pumping velocity calculated from the curl of the bottom stress for day 170 . The thick dashed contours show the BML thickness of $12 \mathrm{~m}$. For both plots, isobaths are shown at 100-m intervals by the black lines, and at 10-m intervals from 60 to $90 \mathrm{~m}$ by the grey lines. The thick black line denotes the coastline, and circles show the mooring locations. Adapted from Kurapov et al. (2005c)

events typically occurred without the presence of any northward winds and were previously unexplained. That ocean response was found to be robust in the model experiments and was dynamically rationalized, through analysis of momentum equation term balances, as being forced by a northward pressure gradient that, in locations dependent on topography, was left unbalanced after the wind relaxation and thus free to accelerate currents northward. Processes with similar dynamics were found embedded in the more complex response to the time-varying winds during the simulation of summer 1982 conditions. That type of model-derived conclusion on shelf flow dynamical behavior would be difficult to extract convincingly from observations, even using data sets as extensive as those from CODE.

Subsequently, circulation over the continental shelf and slope in the region of the WEST field experiment during 
May-June 2001 was simulated by Kuebel Cervantes and Allen (2006). Notable new results included the development in the model velocity fields of a double jet structure in the southward alongshore current. That structure originates just north of Bodega Bay $\left(38.3^{\circ} \mathrm{N}\right)$, seemingly in response to upstream influence from Cordell Bank. Although that feature occurred out of the range of the WEST observations, it is a model-predicted property of the alongshore current that, if real, could have a major impact on the circulation offshore south of Point Reyes. Another new aspect of the study was the use of Lagrangian label fields that are advected by the model-resolved velocities (Kuebel Cervantes et al., 2003) to study the movement of water parcels. Results from that application showed, for example, differences in the source locations for upwelled water north and south of Point Reyes. On the shelf south of Point Reyes, the upwelled water was associated with relatively small parcel displacements, indicating that it was local in origin. North of Point Reyes, the shelf water parcels were characterized by much larger displacements from greater depths and from farther north. These results again illustrate the dominant influence of topography on the characteristics of the shelf flow response in wind-driven systems.

\section{River Plumes and Buoyancy} Forcing

The two most recently completed CoOP projects address the effects of freshwater sources on shelf processes. The Lagrangian Transport and Transformation Experiment (LaTTE) centered on dye-tracking experiments to explore circulation, mixing, and biogeochemical change following water in the Hudson River plume on the New York-New Jersey shelf. The River Influences on Shelf Ecosystems (RISE) project used drifters and intensive twoboat biochemical and physical sampling to address similar issues in the Columbia River plume on the Washington-Oregon shelf. Both projects are indicative of the historical moment: they involve tight interdisciplinary collaboration, and they incorporate realistic circulation and ecosystem modeling for both cruise operation and analysis. The issues studied are of great importance: the Hudson is, "arguably the most contaminated estuary on the East Coast," with 20 million people in its watershed (Wilkin and Lanerolle, 2005), and the Columbia is the primary West Coast battleground between salmon and hydropower.

Prior to LaTTE and RISE, river plume modeling was a well-established subtopic in physical oceanography, but lacking in detailed observations for model testing. A fundamental question being addressed was the formation of "bulge" circulation near the river mouth, which appeared to store an ever-increasing volume of freshwater prior to releasing some to a coastal current heading in the direction of Kelvin wave propagation. Garvine (2001) used a series of idealized numerical experiments to show that bulge circulation was strongly affected by details of the estuarine boundary condition and the coastline. At the time, limitations of computer power forced most models to be run in idealized configurations, with no tides, a rudimentary freshwater source, and idealized winds. Only the largest features could be compared with observations. Did a bulge form? Which direction did it go? The study of
Garcia-Berdeal et al. (2002) clearly demonstrated that varying winds could send the plume in different directions, with the resulting pattern of plume water on the shelf encoding the recent few weeks of wind stress history. Fong and Geyer (2001), arguably the most influential modeling paper of the time, explored the details of plume mixing as a buoyant coastal current was pushed offshore by upwelling-favorable winds. Overall, wind effects on a cyclostrophic or geostrophic buoyant current dominated the discussion of plume physics. Tidal mixing was nearly ignored, and the communities of estuarine and plume modelers rarely overlapped.

The LaTTE and RISE modeling efforts use hydrostatic, primitive-equation numerical models with turbulence submodels, similar to those used in COAST and WEST, including both finite-difference (Choi and Wilkin, 2007; MacCready et al., 2008) and finite-element (Burla et al., in review) implementations. The latter are particularly promising for the resolution of the wide range of spatial scales from continental slope to estuary; typical horizontal grid sizes in the rivers are just a few hundred meters. All the models use realistic bathymetry, river flows, atmospheric forcing (from other reanalysis and forecasting products), and tides (Figure 4). Open boundary conditions, a first-order issue for coastal domains, typically come from large-scale, data-assimilating models such as the Navy Coastal Ocean Model (NCOM). During the corresponding field experiments, LaTTE and RISE models were also run in operational mode, providing daily forecasts during cruises. These forecasts, relayed from shore to the research vessels, were 

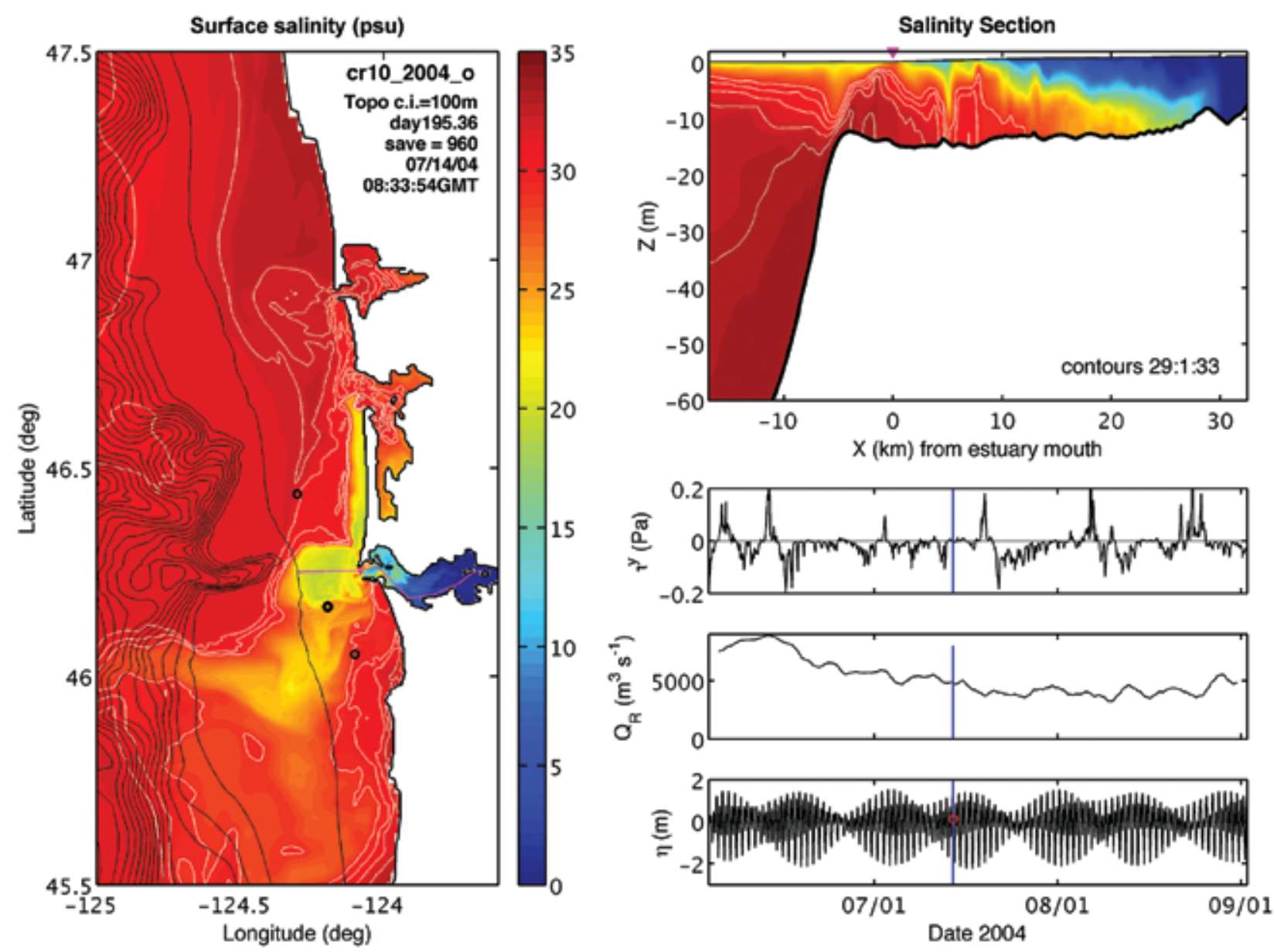

Figure 4. Modeled Columbia River plume salinity field during a wind relaxation period from the RISE project. Topography contours (100-m contour interval) are shown in black and salinity contours ( 1 psu contour interval, from 29 to 33) are white. The timing relative to north/south wind stress, river flow, and tidal height is shown as a blue line in the three lower right panels. The vertical salinity section through the plume and estuary, on the upper right, is taken along the magenta line on the map at left.

very effective in guiding ship movements to sample the rapidly evolving river plumes. The scope of the models (on the order of $200 \times 300$ horizontal grid points, and 20 vertical levels) makes parallel computing standard. Because the models are realistic, they allow direct, quantitative validation against a wide range of observations (MacCready et al., 2008; Burla et al., in review; Liu et al., in review; McCabe et al., in review; Zhang et al., in review (a)). In general, the models show remarkable skill in capturing essential features of the plumes. Although validation against properties such as temperature, salinity, and velocity from a large number of data sources (including mobile platforms) is becoming standard, the models still are not routinely tested against measured mixing rates whose flux divergence governs these properties.

The LaTTE simulations employed both idealized scenarios and adjoint techniques to sort out why the Hudson plume goes where it does (Choi and Wilkin 2007; Zhang et al., in review [a, b]).

RISE simulations were carried out continuously for five years (Burla et al., in review) and so were able to establish comprehensive model statistics for the plume response to forcing.

Both LaTTE (Cahill et al., 2008) and RISE (Banas et al., 2008, in review) used their circulation models as a framework for biogeochemical modeling. Cahill et al. (2008) found that chlorophyll, detritus, and colored dissolved organic matter in the Hudson plume increased the absorption of shortwave radiation, causing enhanced plume stratification. Banas et al. (in review) were able to validate an ecosystem model for RISE against both stocks (nutrients, phytoplankton, and zooplankton) and rates (phytoplankton growth and microzooplankton grazing). Simulations with and without the Columbia River allowed Banas et al. (2008, in review) to quantify the plume effects on the ecosystem. The presence of the plume was found 
to shift productivity offshore and to increase retention, causing a shift toward older communities.

Although a great deal of progress on river plume modeling was made during CoOP, much remains to be done. The intense frontal processes at the plume edge may be crucial to overall mixing and to the concentration of prey for fish. But plume fronts have horizontal scales of just a few tens of meters (Nash and Moum, 2005) and may be inherently nonhydrostatic, both of which put them out of reach of the modeling strategies discussed above. Further, anyone crossing the Columbia River bar in a ship will immediately notice that surface gravity waves are a prominent dynamical feature that has so far been neglected in the models. However, the greatest failings of the models certainly lie in a singularly important area: ecosystem simulation. Errors of advection and mixing have been both minimized and quantified, as described above, albeit still imperfectly. Future progress in coastal ecosystem simulation will come from intensive observations of biological and chemical properties and processes, combined with ongoing integration of this knowledge into model representations.

\section{COASTAL OCEAN MODELING:} THE COOP LEGACY

During the past two decades, the coherent, broad-based, interdisciplinary CoOP program has played a central role in stimulating and supporting the community development of numerical models of coastal ocean circulation and of coupled biophysical models of coastal ecosystems. Of course, many important contributions to this effort have been made with support from other programs; attention here has been necessarily restricted to a brief review of some of the contributions made primarily with support from NSF CoOP.

These community developments in coastal ocean modeling have laid the groundwork for the coastal component of the operational global ocean observing and modeling systems that are planned for the future and whose implementations are now well underway. Pilot ocean forecast systems based on regional implementation of primitiveequation coastal ocean models have been constructed by academic researchers and by federal agencies. Results from COAST (Perlin et al., 2004; Bane et al., 2005) formed part of the motivation for the recent development of coupled ocean-atmosphere models of the coastal zone (Perlin et al., 2007). The anticipated availability of large amounts of real-time data from fixed and mobile in situ ocean-observing assets has stimulated the development of practical data assimilation systems for coastal ocean models. Studies of coastal ocean predictability suggest that the same linear, deterministic dynamics that led to the success of coastal trapped wave theory will-when combined with advanced primitive-equation numerical coastal ocean models and their realistic representations of bathymetry, turbulence, and spatially variable wind fields-lead to useful predictability of coastal ocean flows on time scales up to the predictability limit for the coastal atmosphere (Kim et al., in review). On the scientific side, simplified models of specific physical processes have been and remain an important complement to these progressively more realistic models, which, precisely because of their increasing complexity and realism, are also themselves progressively more difficult to analyze and understand. This active combination of simplified and complex models, spanning the full range of coastal ocean processes and disciplines, was a hallmark of the CoOP program, and comprises a continuing legacy of CoOP that will be of broad, lasting value to the coastal ocean research community, and to all those whose lives and livelihoods are connected to the coastal marine environment.

\section{ACKNOWLEDGEMENTS}

Preparation of this manuscript was supported by the National Science Foundation (NSF) and the Office of Naval Research (ONR), through ONR Grants N00014-05-1-0891 for JSA and RMS and N00014-08-1-0942 for JSA, and NSF Grants OCE-0239089 for PM and OCE-0424516 and 0424602 for RMS. The research reviewed here was primarily supported by the NSF CoOP program. 包

\section{REFERENCES}

Editor's Note: Oceanography does not usually permit citation of articles that are in review; however, because of the rapidly advancing nature of this issue's topics, we are making an exception. Updates on the status of manuscripts cited as in review here will be posted on the CoOP Web site (http://www.skio.usg.edu/coop).

Allen, J.S. 1980. Models of wind-driven currents on the continental shelf. Annual Review of Fluid Mechanics 12:389-433.

Austin, J.A., and S.J. Lentz. 2002. The inner shelf response to wind-driven upwelling and downwelling. Journal of Physical Oceanography 32:2,171-2,193

Banas, N.S., E.V. Lessard, R.M. Kudela, P. MacCready, T.D. Peterson, B.M. Hickey, and E. Frame. In review. Planktonic growth and grazing in the Columbia River plume region: A biophysical 
model study.

Banas, N.S., P. MacCready, and B.H. Hickey. 2008. The Columbia River plume as cross-shelf exporter and along-coast barrier. Continental Shelf Research doi:10.1016/j.csr.2008.03.011.

Bane, J.M., M.D. Levine, R.M. Samelson, S.M. Haines, M.F. Meaux, N. Perlin, P.M. Kosro, and T. Boyd. 2005. Atmospheric forcing of the Oregon coastal ocean during the 2001 upwelling season. Journal of Geophysical Research-Oceans 110(C10S02), doi:10.1029/2004JC002653.

Battisti, D.S., and B. Hickey. 1984. Application of remote wind-forced coastal trapped wave theory to the Oregon and Washington coasts. Journal of Physical Oceanography 14:887-903.

Blumberg, A.F., and G.L. Mellor. 1987. A description of a three-dimensional coastal circulation model. Pp. 1-16 in Three-Dimensional Coastal Ocean Models. N. Heaps, ed., Coastal and Estuarine Science Series, Vol. 4, American Geophysical Union, Washington, DC.

Brink, K.H., and Steering Committee. 1988. Coastal Physical Oceanography: Towards a National Plan. Report of National Science Foundation Gulf Park Meeting, January 1988.

Brink, K.H. 1991. Coastal-trapped waves and winddriven currents over the continental shelf. Annual Reviews of Fluid Mechanics 23:389-412.

Brink, K.H., J.M. Bane, T.M. Church, C.W. Fairall, G.L. Geernaert, D.E. Hammond, S.M. Henrichs, C.S. Martens, C.A. Nittrouer, D.P. Rogers, and others. 1992. Coastal Ocean Processes (CoOP): A Science Prospectus. Woods Hole Oceanographic Institution Technical Report, WHOI-92-18.

Burla, M., A.M. Baptista, Y. Zhang, S. Frolov. In review. Seasonal and inter-annual variability of the Columbia River plume: A perspective enabled by multi-year simulation databases.

Cahill, B., O. Schofield, R. Chant, J. Wilkin, E. Hunter, S. Glenn, and P. Bissett. 2008. Dynamics of turbid buoyant plumes and the feedbacks on near-shore biogeochemistry and physics. Geophysical Research Letters 35(L10605), doi:10.1029/2008GL033595.

Chapman, D.C., and S.J. Lentz. 1997. Adjustment of stratified flow over a sloping bottom. Journal of Physical Oceanography 27(2):340-356.

Chen, Y., R.T. Guza, and S. Elgar. 1997. Modeling spectra of breaking surface waves in shallow water. Journal of Geophysical Research 102(C11):25,035-25,046.

Choi, B.-J., and J.L. Wilkin. 2007. The effect of wind on the dispersal of the Hudson River plume. Journal of Physical Oceanography 37:1,878-1,897.

Church, J.A., N.J. White, A.J. Clarke, H.J. Freeland, and R.L. Smith. 1986. Coastal-trapped waves on the East Australian continental shelf. Part II: Model verification. Journal of Physical Oceanography 16:1,945-1,957.

Fong, D.A., and W.R. Geyer. 2001. Response of a river plume during an upwelling favorable wind event. Journal of Geophysical Research 106:1,067-1,084.

Gan, J., and J.S. Allen. 2002a. A modeling study of shelf circulation off northern California in the region of the Coastal Ocean Dynamics Experiment: Response to relaxation of upwelling winds. Journal of Geophysical Research 107(C9), 3123, doi:10.1029/2000JC000768.

Gan, J., and J.S. Allen. 2002b. A modeling study of shelf circulation off northern California in the region of the Coastal Ocean Dynamics Experiment: Simulations and comparisons with observations. Journal Geophysical Research 107(C11), 3184, doi:10.1029/2001JC001190.

Gan, J., and J.S. Allen. 2005. Modeling upwelling circulation off the Oregon coast. Journal of Geophysical Research 110(C10S07), doi:10.1029/2004JC002692.

Garcia-Berdeal, I., B. M. Hickey, and M. Kawase. 2002. Influence of wind stress and ambient flow on a high discharge river plume. Journal of Geophysical Research 107(13), doi:10.1029/2001JC000932.

Garvine, R.W. 2001. The impact of model configuration in studies of buoyant coastal discharge. Journal of Marine Research 59:193-225.

Gill, A.E., and A.J. Clarke. 1974. Wind-induced upwelling, coastal currents and sea level changes. Deep-Sea Research 21:325-345.

Gill, A.E., and E.H. Schumann. 1974. The generation of long shelf waves by the wind. Journal of Physical Oceanography 4(1):83-90.

Halliwell, G.R., and J.S. Allen. 1984. Large-scale sea level response to atmospheric forcing along the west coast of North America, summer 1973. Journal of Physical Oceanography 14:864-886.

Heaps, N.S. 1987. Three-Dimensional Coastal Ocean Models. American Geophysical Union, Washington DC, $208 \mathrm{pp}$.

Kim, S., R.M. Samelson, and C. Snyder. In review. Ensemble-based estimates of the predictability of wind-driven coastal ocean flow over topography.

Kuebel Cervantes, B.T., J.S. Allen, and R.M. Samelson. 2003. A modeling study of Eulerian and Lagrangian aspects of shelf circulation off Duck, North Carolina. Journal of Physical Oceanography 33:2,070-2,092.

Kuebel Cervantes, B.T., and J. S. Allen. 2006. Numerical model solutions of continental shelf flows off Northern California. Deep-Sea Research Part II 53:2,956-2,984.

Kurapov, A.L., J.S. Allen, G.D. Egbert, R.N. Miller, P.M. Kosro, M. Levine, and T. Boyd. 2005a. Distant effect of assimilation of moored currents into a model of coastal wind-driven circulation off Oregon. Journal of Geophysical Research 110(C02022), doi:10.1029/2003JC002195.

Kurapov, A.L., J.S. Allen, G.D. Egbert, R.N. Miller, P.M. Kosro, M.D. Levine, T. Boyd, and J.A. Barth. 2005b. Assimilation of moored velocity data in a model of coastal wind-driven circulation off Oregon: Multivariate capabilities. Journal of Geophysical Research 110(C10S08), doi:10.1029/2004JC002493.

Kurapov, A.L., J.S. Allen, G.D. Egbert, and R.N. Miller. 2005c. Modeling bottom mixed layer variability on the mid-Oregon shelf during summer upwelling. Journal of Physical Oceanography 35:1,629-1,649.

Liu, Y., P. MacCready, B.M. Hickey, E.P. Dever, P.M. Kosro, and N.S. Banas. In review. Evaluation of a coastal ocean circulation model for the Columbia River plume in summer 2004.

MacCready, P., N.S. Banas, B.M. Hickey, E.P. Dever, and Y. Liu. 2008. A model study of tide- and windinduced mixing in the Columbia River estuary and plume. Continental Shelf Research, doi:10.1016/j. csr.2008.03.015

McCabe, R.M., P. MacCready, and B.M. Hickey. In review. Ebb tide dynamics and spreading of a large river plume.

Mellor, G.L., and T. Yamada. 1982. Development of a turbulent closure model for geophysical problems. Reviews of Geophysics 21:851-875.

Mitchum, G.T., and A.J. Clarke. 1986. Evaluation of frictional, wind-forced long-wave theory on the West Florida shelf. Journal of Physical Oceanography 16:1,029-1,037.

Nash, J.D., and J.N. Moum. 2005. River plumes as a source of large-amplitude internal waves in the coastal ocean. Nature 437:400-403, doi:10.1038/ nature03936.

O'Brien, J.J., and H.E. Hurlburt. 1972. A numerical model of coastal upwelling. Journal of Physical Oceanography 2:14-26.

Oke, P.R., J.S. Allen, R.N. Miller, G.D. Egbert, J.A. Austin, J.A. Barth, T.J. Boyd, P.M. Kosro, and M.D. Levine. 2002. A modeling study of the three-dimensional continental shelf circulation off Oregon. I. Model-data comparisons. Journal of Physical Oceanography 32:1,360-1,382.

Peffley, M.B., and J.J. O’Brien. 1976. A three-dimensional simulation of coastal upwelling off Oregon. Journal of Physical Oceanography 6:164-180.

Perlin, N., R.M. Samelson, and D.B. Chelton. 2004. Scatterometer and model wind and wind stress in the Oregon-northern California coastal zone. Monthly Weather Review 132:2,110-2,129.

Perlin, N., E. Skyllingstad, R. Samelson, and P. Barbour. 2007. Numerical simulation of air-sea coupling during coastal upwelling. Journal of Physical Oceanography 37:2,081-2,093.

Shchepetkin, A.F., and J.C. McWilliams. 2005. The regional oceanic modeling system (ROMS): A split-explicit, free-surface, topography-followingcoordinate oceanic model. Ocean Modelling 9:347-404.

Spitz, Y.H., J.S. Allen, and J. Gan. 2005. Modeling of ecosystem processes on the Oregon shelf during the 2001 summer upwelling. Journal of Geophysical Research 110(C10S17), doi:10.1029/2005JC002870.

Wilkin, J., and L. Lanerolle. 2005. Ocean forecast and analysis models for coastal observatories. Pp. 549572 in Ocean Weather Forecasting: An Integrated View of Oceanography. E. Chassignet and J. Verron, eds, Springer.

Zhang, W.G., J.L. Wilkin, and R.J. Chant. In review(a). Modeling the pathways and mean dynamics of river plume dispersal in the New York Bight.

Zhang, W.G., J.L. Wilkin, J.C. Levin, and H.G. Arango. In review(b). An adjoint sensitivity study of buoyancy- and wind-driven circulation on the New Jersey inner shelf. 